\title{
Anti-inflammatory IL-10 is upregulated in both hemispheres after experimental ischemic stroke: Hypertension blunts the response
}

\author{
Abdelrahman Y Fouda', Anna Kozak', Ahmed Alhusban' ${ }^{1}$, Jeffrey A Switzer ${ }^{2}$ and Susan C Fagan ${ }^{1,2^{*}}$
}

\begin{abstract}
Background: Exogenous administration of the anti-inflammatory cytokine, interleukin 10 (IL-10), is known to promote neuroprotection and mitigate neuroinflammation after ischemia. However, endogenous expression and localization of IL-10 and its receptor (IL-10R) in the post-ischemic brain are still to be elucidated. In this investigation we aimed at determining the temporospatial expression of IL-10 in the rat brain relative to its systemic levels after ischemic stroke.
\end{abstract}

Methods: Wistar rats were subjected to either permanent (pMCAO) or 3-h temporary (tMCAO) middle cerebral artery occlusion and euthanized at either 24 or $72 \mathrm{~h}$. IL-10/IL-10R levels were quantified in ischemic and contralesional hemispheres and compared to shams using multiplex bead array and Western blotting, respectively. Localization of IL-10/IL-10R with markers for neurons, microglia, astrocytes \& endothelial cells were examined using double labeling immunofluorescence. IL-10 was also quantified in the brain tissue of spontaneously hypertensive rats (SHRs) at $24 \mathrm{~h}$ after tMCAO.

Results: After both PMCAO and TMCAO in Wistars, IL-10 was significantly upregulated in both hemispheres by $\approx 50 \%$ at $24 \mathrm{~h}$ while IL-10R expression was significantly decreased only at $72 \mathrm{~h}$ in the ischemic hemisphere. IL-10 and IL-10R expression highly co-localized with viable neurons in the ischemic penumbra and contralesional hemisphere. In hypertensive rats, IL-10 showed no significant contralesional upregulation and declined significantly in the ischemic side at $24 \mathrm{~h}$ post-ischemia.

Conclusion: Our data highlights the involvement of the ischemic and contralesional neurons in the endogenous anti-inflammatory response after ischemic stroke through increased production of IL-10. This increase in IL-10 is blunted in hypertensive animals and may contribute to worse outcomes.

\section{Introduction}

Innate inflammatory response is a major component of the pathophysiology of ischemic stroke [1,2]. While preclinical studies have shown beneficial effects with adopting an anti-inflammatory approach in the treatment of ischemic stroke, results from clinical trials have been disappointing with no benefit or even worsened outcome in ischemic stroke patients after anti-inflammatory intervention [3,4]. This can be partly explained by the lack

\footnotetext{
* Correspondence: sfagan@gru.edu

${ }^{1}$ Charlie Norwood VA Medical Center, College of Pharmacy, University of Georgia and Center for Pharmacy and Experimental Therapeutics, Augusta, GA, USA

2Department of Neurology, Medical College of Georgia, Georgia Regents University, Augusta, GA, USA
}

of full understanding of the endogenous anti-inflammatory response in the brain following ischemia.

Animal studies have confirmed the anticipated neuroprotective role of the anti-inflammatory cytokine, interleukin 10 (IL-10), in ischemic stroke. Administration of exogenous IL-10 centrally and systemically decreases the infarct size in rats after permanent focal ischemia [5], while IL-10 knockout mice showed larger infarct volume following middle cerebral artery occlusion [6]. Moreover, post-ischemic IL-10 gene transfer attenuated brain infarction in rats subjected to focal and global ischemia [7]. In in-vitro models, IL-10 protects murine cortical and cerebellar neurons from excitotoxic damage and oxygen glucose deprivation by activating survival 
pathways [6,8]. Clinically, lower IL-10 plasma levels have been associated with increased risk of stroke [9]. However, IL-10 is increased in the serum and CSF of patients after ischemic stroke with conflicting reports on its correlation with improved versus worsened outcome [10-12]. It is likely that the ratio of inflammatory versus

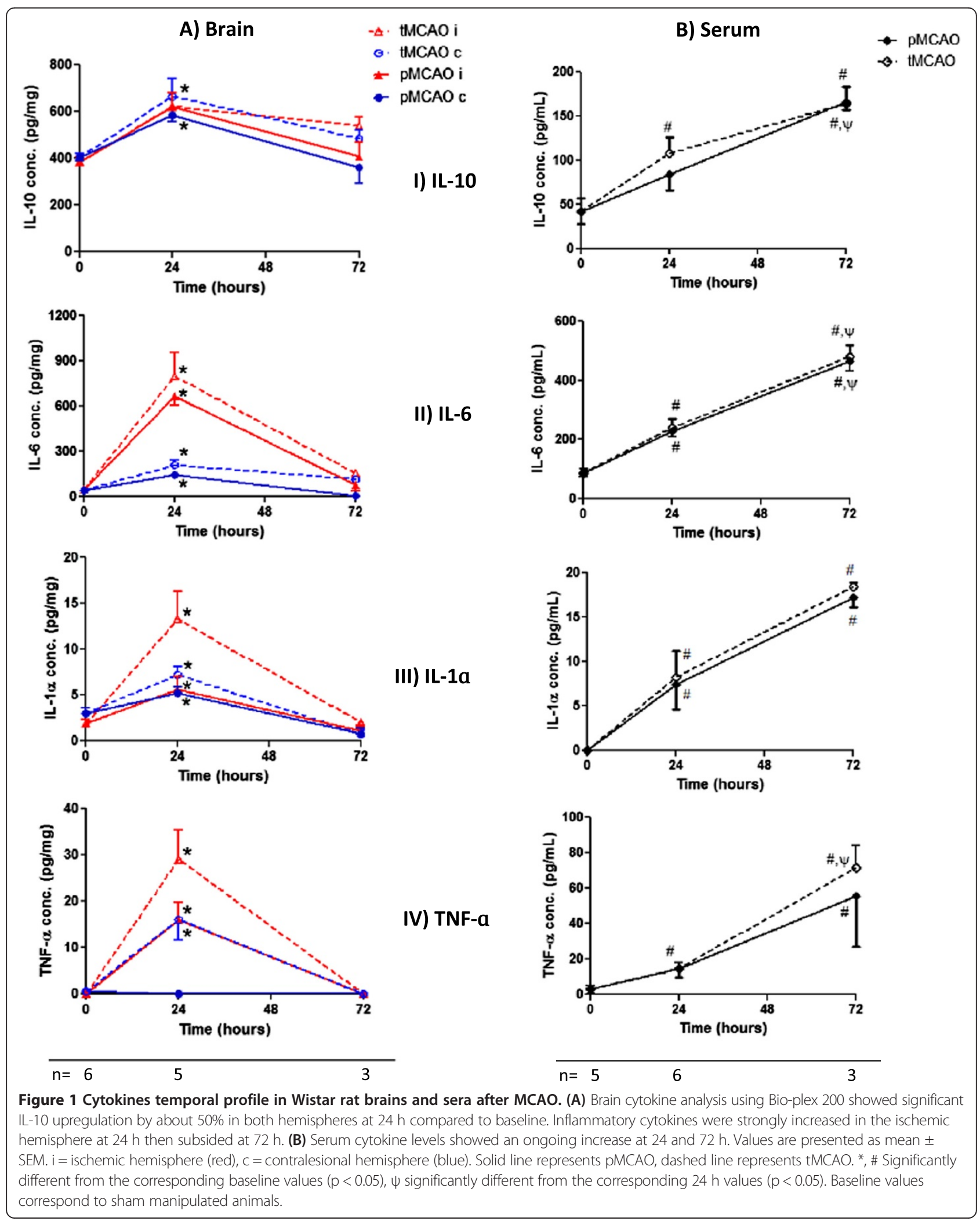


anti-inflammatory cytokines may give a better picture of overall status in the acute stroke period.

Despite existing knowledge, the temporospatial expression and cellular sources of endogenous IL-10 and its receptor following ischemic stroke are still not known. In the current study, we aimed to elucidate the expression and cellular sources of IL-10 and its receptor in brain tissue of Wistar rats at 24 and $72 \mathrm{~h}$ post ischemia. In addition, we examined the change in IL-10 levels after stroke in hypertensive rats.

\section{Methods}

Middle cerebral artery occlusion (MCAO)

All experimental procedures were approved by the institutional Animal Care and Use Committee of the Charlie Norwood Veterans Affairs Medical Center. 36
I)

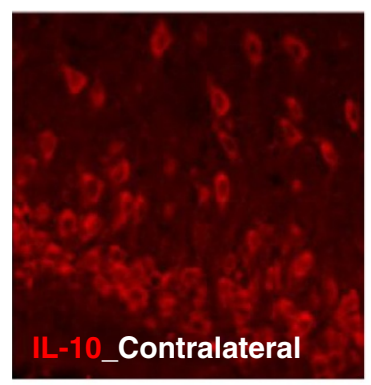

II)

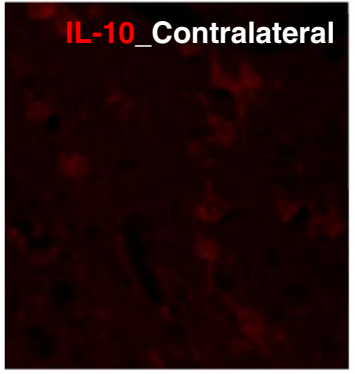

III)

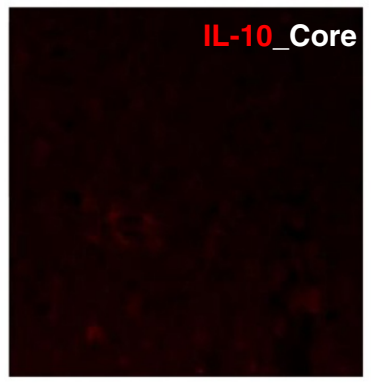

IV)

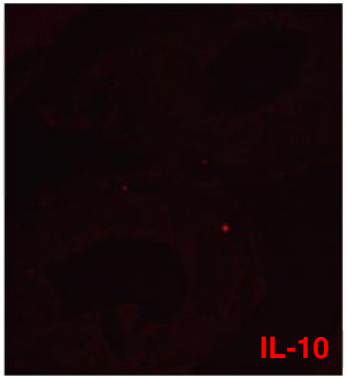

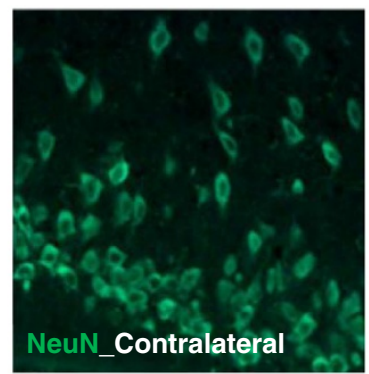
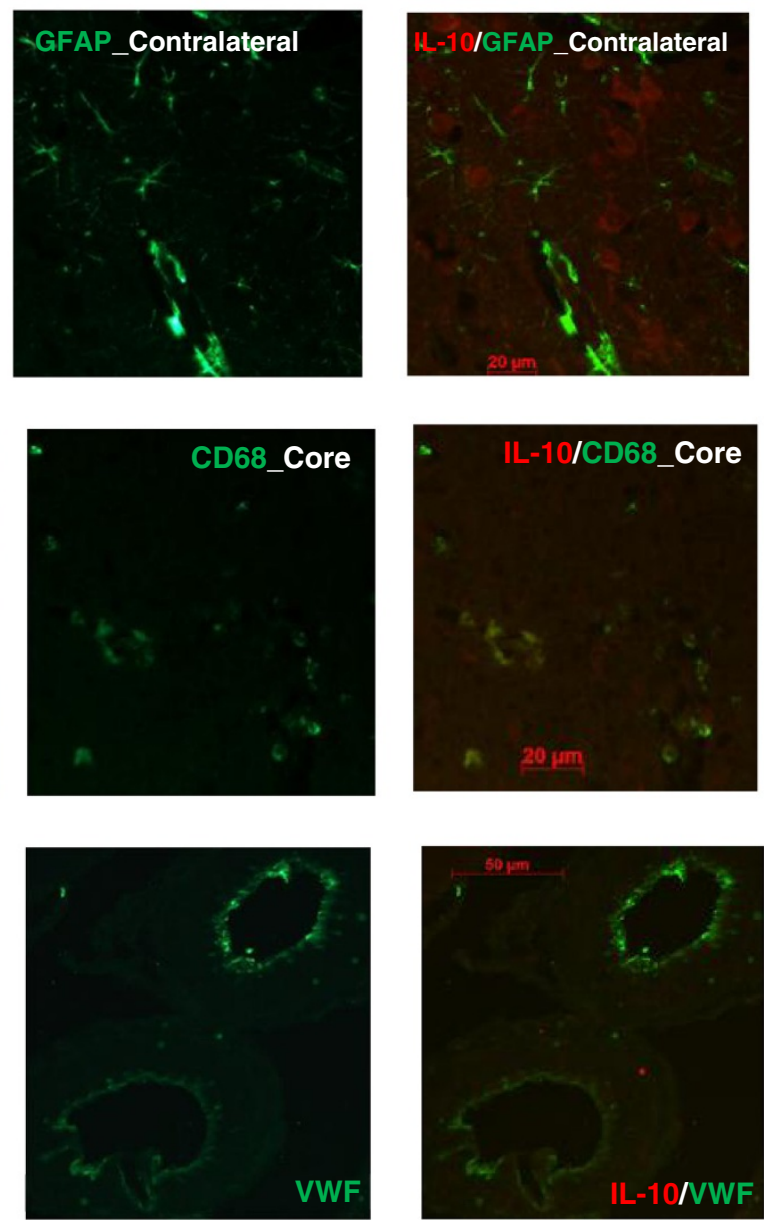

Figure 2 Immunofluorescent localization of IL-10 in Wistar rat brains after tMCAO. IL-10 strongly co-localized with NeuN in the ischemic penumbra and contralesional cortical, striatal and hippocampal neurons with less expression in the ischemic core neurons or activated microglia (CD68). IL-10 showed no co-localiztion with markers of astrocytes (GFAP) or endothelial cells (VWF). Images were taken from $24 \mathrm{~h}$ brain sections. $72 \mathrm{~h}$ brain sections showed similar pattern. $\mathrm{N}=4$ per group. 
Adult male Wistars and 16 spontaneously hypertensive (SHR) rats (270-320 g) underwent permanent (pMCAO) $(\mathrm{n}=9), 3$ h-temporary $(\mathrm{tMCAO})(\mathrm{n}=25)$ middle cerebral artery occlusion using the suture model, or sham operation $(n=18)$ as described [13]. Animals were sacrificed at 24 or $72 \mathrm{~h}$ and brain tissues were collected for molecular analysis and immunofluorescence.

\section{Multiplex array system}

Cytokine levels in brain homogenates and sera from Wistar rats were simultaneously analyzed using a multiplex array system (Bio-Plex 200; Bio-Rad) according to the manufacturer instructions. After calibrating the instrument, $25 \mu \mathrm{g}$ for brain and $50 \mu \mathrm{L}$ of sera were run in triplicates using 4-plex assay kits for tissue and sera respectively and compared to serial dilutions of the standards provided with the kits. Concentrations were determined using the Bio-Plex Manager software program (Bio-Rad version 4.1.1). Cytokine levels below detection limit were assigned a zero value.

\section{Enzyme linked immunosorbent assay (ELISA)}

Brain homogenates from spontaneously hypertensive rats (SHRs) were analyzed for IL-10 using Rat IL-10 sandwich ELISA (RayBiotech) according to the manufacturer's instructions.

\section{Western blotting}

Brain homogenate aliquots containing $50 \mu \mathrm{g}$ protein were separated on SDS-PAGE, transferred to nitrocellulose membranes and probed with anti-IL-10R $\alpha$ rabbit antirat antibody (1:500, Santa Cruz) [13]. Protein bands were quantified and normalized to $\beta$-actin using ImageJ software.

\section{Double-labelling immunofluorescence}

$4 \mu \mathrm{m}$ paraffin embedded brain sections were processed simultaneously. After rehydration, the sections were boiled in sodium citrate buffer $(\mathrm{pH}$ 6.0) for antigen retrieval, permeabilized and blocked in $10 \%$ horse serum with $1 \% \mathrm{BSA}$ in $\mathrm{TBS}$ for $2 \mathrm{~h}$ at $25^{\circ} \mathrm{C}$. For double labeling, two primary antibodies were incubated simultaneously overnight at $4^{\circ} \mathrm{C}$ at the following dilutions: rabbit antiIL-10 (1/100; invitrogen), rabbit anti-IL-10R $\alpha(1 / 100$; Santa Cruz), mouse anti-neuronal nuclei (NeuN) (1/ 100; Millipore) a marker for neurons, mouse anti-glial fibrillary acidic protein (GFAP) (1/300; Sigma-Aldrich) a marker for astrocytes, mouse anti-CD68 (1/100; AbD Serotec) a marker for reactive microglia/macrophages, and goat anti-Von Willebrand factor (VWF) (1/100; Santa Cruz) a marker for endothelial cells. After washing, slides were incubated with fluorescent secondary antibodies, cover slipped with Vectashield mounting medium (Vector Laboratories) and viewed using Zeis Axio
Observer.Z1 fluorescent microscope. Negative controls were prepared by omitting the primary antibodies.

\section{Statistical analysis}

The results are expressed as the means \pm SEM, and statistical analyses were performed with Student's t-test using NCSS 2007 software. $P$ values less than 0.05 were considered significant.

\section{Results}

\section{IL-10 is upregulated in both hemispheres at $24 \mathrm{~h}$ after} MCAO in Wistars

We used the Multiplex array system (Bio-plex 200) to study the cytokine temporal profile in brains and sera of Wistar rats at subacute $(24 \mathrm{~h})$ and delayed $(72 \mathrm{~h})$ time points in response to MCAO. IL-10 significantly increased by about $50 \%$ in both hemispheres at $24 \mathrm{~h}$ after both permanent and temporary MCAO. On the other hand, inflammatory cytokines (IL-6, IL-1 $\alpha$ \& TNF- $\alpha$ ) fold increase was much higher in the lesional hemisphere at $24 \mathrm{~h}$ with more upregulation after $\mathrm{tMCAO}$ then subsided at $72 \mathrm{~h}$ (Figure 1A). All cytokine serum levels were significantly upregulated at $24 \mathrm{~h}$ and further increased by $2-3$ fold at $72 \mathrm{~h}$ (Figure 1B).

Neurons are the main source of IL-10 after MCAO

Using double labeling immunofluorescence, we explored the spatial expression of IL-10 in sham Wistar rat brains and at 24/72 h after tMCAO using markers for neurons,

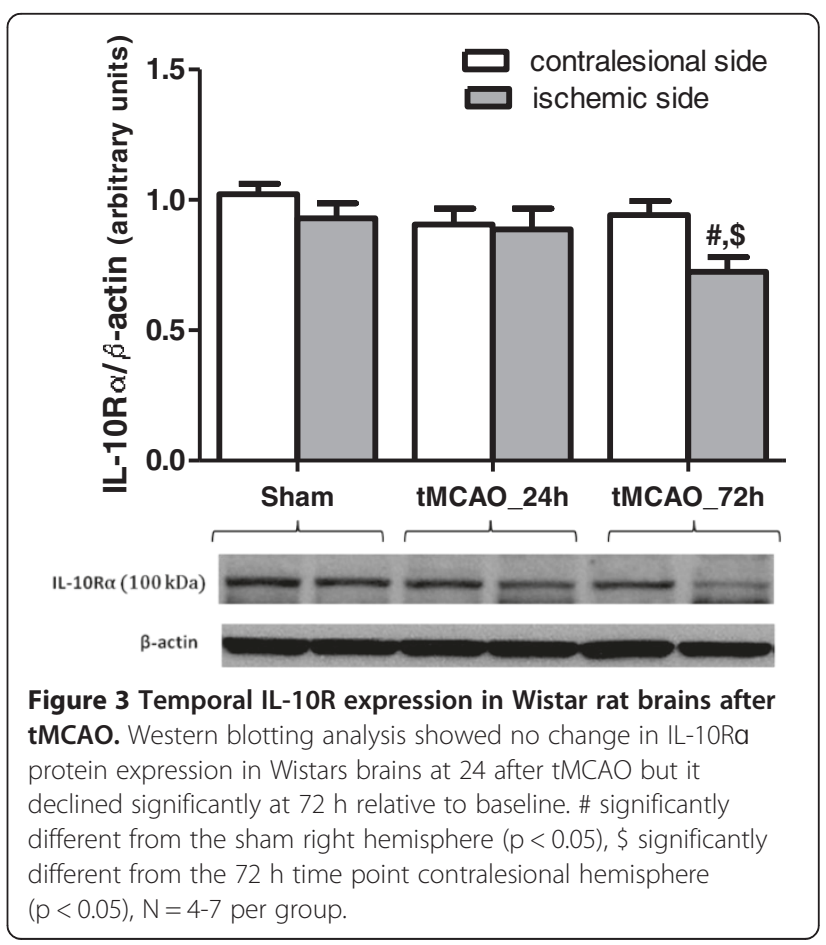


astrocytes, activated microglia and endothelial cells. IL-10 showed strong co-localization with the neuronal marker, $\mathrm{NeuN}$, in the ischemic penumbra and contralesional cortical, striatal and hippocampal neurons with less expression in the ischemic core neurons or activated microglia (CD68). IL-10 showed no co-localization with markers of astrocytes (GFAP) or endothelial cells (VWF) at the time points studied (Figure 2).

\section{Temporal and spatial interleukin 10 receptor (IL-10R)} protein expression after $\mathrm{tMCAO}$ in Wistars

IL-10 executes its pleiotropic actions through binding to IL-10 receptor complex that is composed of two chains, IL-10R $\alpha$ and IL-10R $\beta$. Of the two receptor subunits, IL-10R $\alpha$ is specific for the IL-10 signaling pathway while IL-10R $\beta$ is part of other cytokine receptor complexes as well [14].

To test whether stroke modulates IL-10R $\alpha$ expression, we performed Western blotting and immunostaining on Wistar brains subjected to tMCAO. IL-10R $\alpha$ protein expression did not change at $24 \mathrm{~h}$ after tMCAO relative to baseline. However, it significantly declined in the stroked hemisphere at $72 \mathrm{~h}$ (Figure 3). Immunflourescent co-localization showed strong IL-10R expression in the neurons (NeuN) and endothelial cells (VWF) of sham operated animals and this expression was extended to activated microglia (CD68) after tMCAO (Figure 4). l)

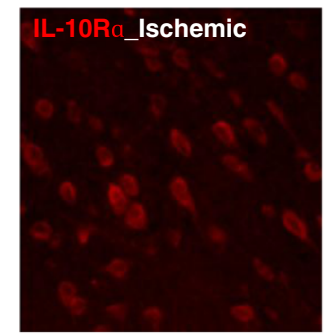

II)

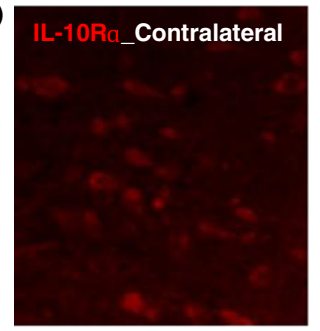

III)

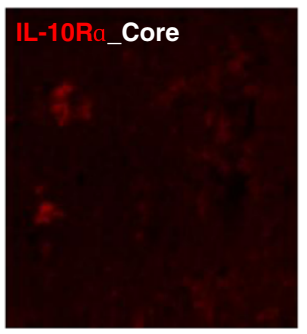

IV)

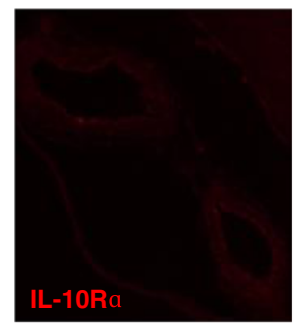

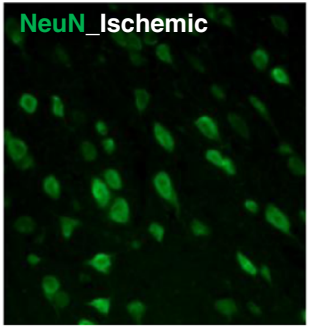
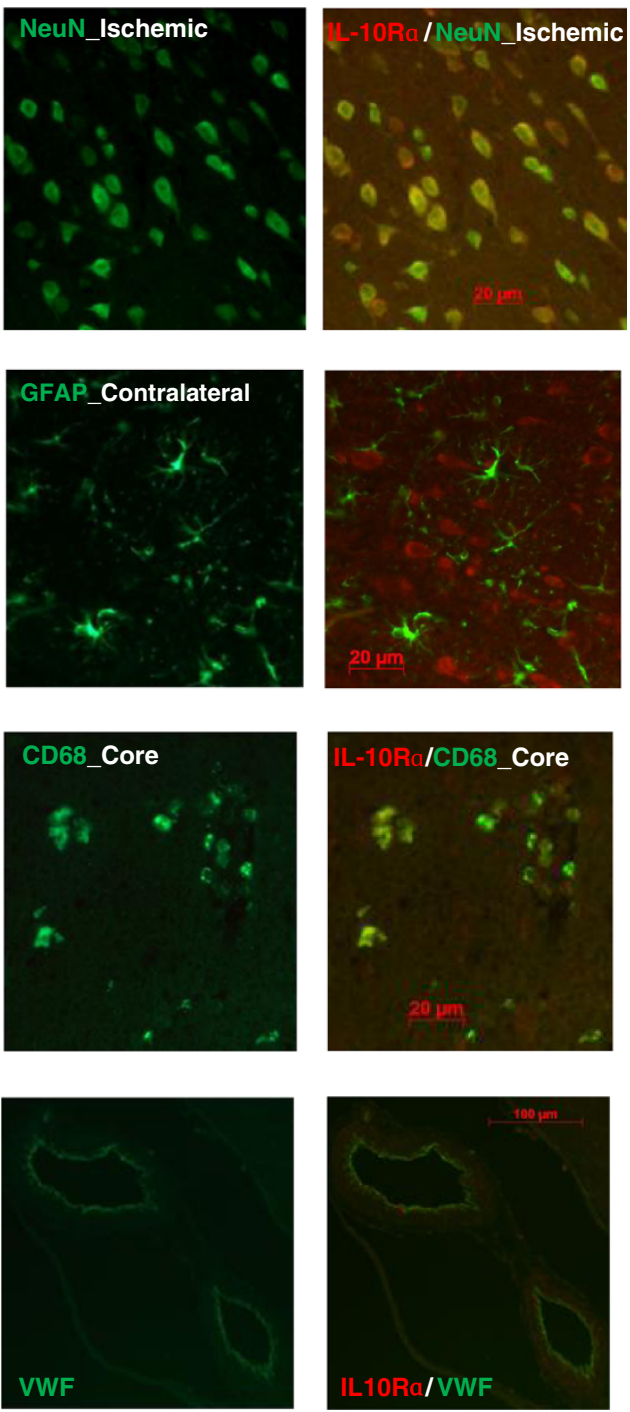

Figure 4 Immunofluorescent localization of IL-10R in Wistar rat brains after tMCAO. IL-10Ra strongly expressed in neurons (NeuN) and endothelial cells (WWF) of sham and stroked animals in addition to activated microglia/macrophages (CD68) after tMCAO but not astrocytes (GFAP). Images were taken from $24 \mathrm{~h}$ brain sections. $72 \mathrm{~h}$ brain sections showed similar results. $\mathrm{N}=4 \mathrm{per}$ group. 


\section{IL-10 upregulation is lost in hypertensive animals after MCAO}

Hypertension is associated with a pro-inflammatory milieu. For this reason, we examined the IL-10 levels in SHRs brains after sham operation and at $24 \mathrm{~h}$ after $3 \mathrm{~h}$-tMCAO. Baseline IL-10 levels were less in hypertensive rats compared to Wistars. After MCAO, IL-10 was significantly decreased in the stroked hemisphere together with a slight increase in the contralesional hemisphere that was not significant (Figure 5).

\section{Discussion}

This study investigated the endogenous expression of IL-10 and its receptor in the rat brain after experimental stroke. We show, for the first time, that IL-10 is upregulated in both hemispheres at $24 \mathrm{~h}$ after both $\mathrm{p}$ - and $\mathrm{t}-\mathrm{MCAO}$, in contrast to the inflammatory cytokines that were upregulated on the ischemic side. Moreover, immunostaining studies showed neurons to be the major source of IL-10 and its receptor. IL-10 receptor was also expressed in microglia \& endothelial cells in accordance with the literature $[8,15]$. Together with previous reports of localization of IL-6 and its receptor with ischemic brain neurons [16], our data highlights the involvement of neurons in the ischemic inflammatory response being both the source and target of cytokine actions.

The discrepancies in the cytokine levels between brain and serum at $72 \mathrm{~h}$ point to the strong involvement of the systemic immune response in cytokine production at this later time point and that serum cytokine levels do

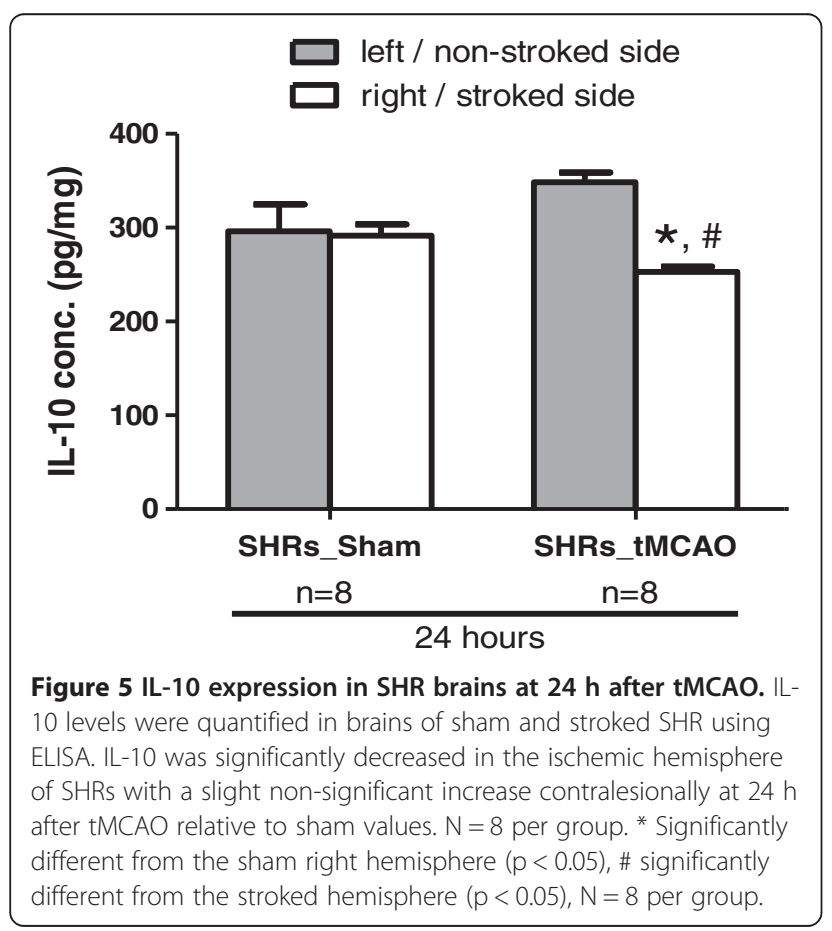

not necessarily reflect the local inflammation ongoing in the brain.

Hypertension is a major risk factor for ischemic stroke. The low baseline levels and loss of early upregulation of IL-10 in spontaneously hypertensive rats (SHRs) $24 \mathrm{~h}$ after MCAO shows an impaired anti-inflammatory response after ischemic stroke that might be associated with the impaired recovery and worsened outcome in these animals [17].

In summary, our study highlights the contribution of the ischemic and contralesional neurons to the antiinflammatory response after ischemic stroke through upregulation of IL-10. This outcome is lost under the inflammatory milieu of hypertension. Taken together, these findings suggest that endogenous IL-10 could be a therapeutic target to reduce ischemic damage especially under hypertension. Despite this, the study is limited to the time points examined and does not rule out a possible late role of IL-10 after 3 days post-ischemia involving other brain cells. While a recent study has underscored the functional protective role of IL-10 in ischemic stroke through ameliorating brain inflammation [18], further investigations are needed to examine the mechanisms involved in IL-10 upregulation post-ischemia.

\section{Competing interests}

The authors declare no competing interests.

\section{Authors' contributions}

AF - Participation in the study design, conduct of experiments, data analysis, and drafting of the manuscript. AK - participation in the study design, conduct of experiments and data analysis. AA - participation in the conduct of experiments and data analysis. JAS - critically revising the manuscript and final edits to the manuscript. SCF - Study design, critically revising the manuscript and final edits to the manuscript. All authors read and approved the final manuscript.

\section{Acknowledgements}

This work was funded by Veterans Affairs Merit Review (BX000891) \& RO1NS063965 to SCF.

Received: 16 October 2013 Accepted: 11 November 2013 Published: 13 November 2013

\section{References}

1. del Zoppo G, Ginis I, Hallenbeck JM, ladecola C, Wang X, Feuerstein GZ: Inflammation and stroke: putative role for cytokines, adhesion molecules and iNOS in brain response to ischemia. Brain pathol 2000, 10:95-112

2. Fagan SC, Hess DC, Machado LS, Hohnadel EJ, Pollock DM, Ergul A: Tactics for vascular protection after acute ischemic stroke. Pharmacotherapy 2005, 25:387-395.

3. del Zoppo GJ: Acute anti-inflammatory approaches to ischemic stroke. Ann N Y Acad Sci 2010, 1207:143-148.

4. Jord $\tilde{A} j n$ J, Segura T, Brea D, Galindo M, Castillo J: Inflammation as therapeutic objective in stroke. Curr pharm des 2008, 14:3549-3564.

5. Spera PA, Ellison JA, Feuerstein GZ, Barone FC: IL-10 reduces rat brain injury following focal stroke. Neurosci Lett 1998, 251:189-192.

6. Grilli M, Barbieri I, Basudev H, Brusa R, Casati C, Lozza G, Ongini E: Interleukin-10 modulates neuronal threshold of vulnerability to ischaemic damage. Eur j neurosci 2000, 12:2265-2272.

7. Ooboshi H, Ibayashi S, Shichita T, Kumai Y, Takada J, Ago T, Arakawa S, Sugimori H, Kamouchi M, Kitazono T, lida M: Postischemic gene transfer of interleukin-10 protects against both focal and global brain ischemia. Circulation 2005, 111:913-919. 
8. Sharma S, Yang B, Xi X, Grotta JC, Aronowski J, Savitz SI: IL-10 directly protects cortical neurons by activating PI-3 kinase and STAT-3 pathways. Brain res 2011, 1373:189-194.

9. Van Exel E, Gussekloo J, De Craen AJM, Bootsma-Van Der Wiel A, Frölich M, Westendorp RGJ: Inflammation and stroke: the Leiden 85-Plus study. Stroke 2002, 33:1135-1138.

10. Tarkowski E, Rosengren L, Blomstrand C, Wikkelsö C, Jensen C, Ekholm S, Tarkowski A: Intrathecal release of pro- and anti-inflammatory cytokines during stroke. Clin exp immunol 1997, 110:492-499.

11. Chang LT, Yuen CM, Liou CW, Lu CH, Chang WN, Youssef AA, Yip HK: Link between interleukin-10 level and outcome after ischemic stroke. Neuroimmunomodulation 2010, 17:223-228.

12. Vila N, Castillo J, Davalos A, Esteve A, Planas AM, Chamorro A: Levels of anti-inflammatory cytokines and neurological worsening in acute ischemic stroke. Stroke 2003, 34:671-675.

13. Guan W, Somanath PR, Kozak A, Goc A, El-Remessy AB, Ergul A, Johnson $\mathrm{MH}$, Alhusban A, Soliman S, Fagan SC: Vascular protection by angiotensin receptor antagonism involves differential VEGF expression in both hemispheres after experimental stroke. PloS one 2011, 6:e24551.

14. Sabat R, Grutz G, Warszawska K, Kirsch S, Witte E, Wolk K, Geginat J: Biology of interleukin-10. Cytokine growth factor rev 2010, 21:331-344.

15. Londono D, Carvajal J, Strle K, Kim KS, Cadavid D: IL-10 Prevents apoptosis of brain endothelium during bacteremia. J immunol (Baltimore, Md: 1950) 2011, 186:7176-7186.

16. Suzuki S, Tanaka K, Nogawa S, Nagata E, Ito D, Dembo T, Fukuuchi Y: Temporal profile and cellular localization of interleukin-6 protein after focal cerebral ischemia in rats. I cereb blood flow metab: official journal of the International Society of Cerebral Blood Flow and Metabolism 1999, 19:1256-1262.

17. Barone FC, Price WJ, White RF, Willette RN, Feuerstein GZ: Genetic hypertension and increased susceptibility to cerebral ischemia. Neurosci biobehav rev 1992, 16:219-233.

18. Perez-de Puig I, Miro F, Salas-Perdomo A, Bonfill-Teixidor E, Ferrer-Ferrer M, Marquez-Kisinousky L, Planas AM: IL-10 deficiency exacerbates the brain inflammatory response to permanent ischemia without preventing resolution of the lesion. J Cereb Blood Flow Metab 2013. doi: 10.1038/ jcbfm.2013.155. [Epub ahead of print].

doi:10.1186/2040-7378-5-12

Cite this article as: Fouda et al: Anti-inflammatory IL-10 is upregulated in both hemispheres after experimental ischemic stroke: Hypertension blunts the response. Experimental \& Translational Stroke Medicine 2013 5:12.

\section{Submit your next manuscript to BioMed Central and take full advantage of:}

- Convenient online submission

- Thorough peer review

- No space constraints or color figure charges

- Immediate publication on acceptance

- Inclusion in PubMed, CAS, Scopus and Google Scholar

- Research which is freely available for redistribution 